\title{
Research on Entrepreneurship Ability Ascending Path in Emerging Tech- nology Enterprises in Our Country
}

\author{
Dayong $\mathrm{Xu}^{*}$
}

Department of Business Administration, University of Science and Technology Liaoning, Anshan, Liaoning, 114051, China

\begin{abstract}
The emerging technology enterprises are the important supporter that emerging technology evolves into emerging industry, emerging technology enterprises entrepreneurial ability promotion path is a very complex fuzzy concept, how to improve entrepreneurial ability and this article defines that entrepreneurial ability has become a problem for emerging technology enterprises to keep their competitive advantage to be solved, this article has built research framework and structural equation model based on the theoretical analysis and selected 492 emerging technology enterprises as research objects. It quantitatively discusses the influence which market orientation, entrepreneurial learning and innovative way have on entrepreneurship. According to the result, to modify the model, come to the conclusion that China's emerging technology enterprise business ability and experience, the path of ascension is beneficial to provide reference for the same type enterprises in our country for reference, which will improve the development of emerging industry.
\end{abstract}

Keywords: Emerging technology enterprises, entrepreneurial ability, structural equation model, the path of ascension.

\section{INTRODUCTION}

The emerging industry is based on major technical breakthroughs and development needs with knowledge technology intensive, less material resources consumption, big growth potential and good comprehensive benefit. It plays an important role in leading and driving the social and economic development $[1,2]$. Premier wen jiabao stressed that we could select and develop the emerging strategic industry with international vision and strategic thinking. As the new direction of today's technology innovation management at home and abroad, emerging technologies has become the important theory to develop strategic emerging industry in China.

Emerging technology based on science is an innovation, which is likely to create a new industry or remould an existing industry. It has a high degree of uncertainty and complexity, has strong era, commercialization and the characteristics of the creative reshaping of traditional industry. Zhao zhenyuan (2004) thinks emerging technologies also have driven sexual characteristics. It has three elements: (1) The technology is in formation or development. (2) It is high technology. (3) It could make an important impact on economic structure or industry development. The development of emerging technology companies need to continue to update and reconstruct their own entrepreneurship, this must cause the dynamic evolution of corporate entrepreneurship [3-6]. It brings enormous challenge also opportunities for our country and firms. Companies those who are good at developing and managing emerging technology will make an unexpected success. We can say emerging technology research support a good breakthrough for the entrepreneurial ability of companies $[7,8]$. In the process of promoting the development of emerging technology, the emerging technology, in turn, will make the corresponding changes in the enterprise compentence. The change of ability will make an influence on improving the competition advantage [9-13]. We can say no emerging technology, no emerging industry. Emerging technology is the key to ensure emerging technology firms' entrepreneurship and promote the development of emerging industry ultimately. Therefore, it's necessary for us to carry on the further study of the path of ascension in emerging technology enterprises' entrepreneurship.

\section{THE PRESENT SITUATION OF THE STUDIES AND ASSUMPTIONS DEDUCTION}

Emerging technology enterprises face the fierce competition in the changing environment; constant adjustment innovation has become the key strategic issue which needs to think about. In order to improve the entrepreneurial ability, companies must keep pace with the times of the entrepreneurial learning. Scholars' focus on "entrepreneurial learning" could be dated back to the earliest study by March and Simon (1958), it's concept was put forward formally by Agryris and Schon (1978), the concept of entrepreneurial learning gradually come to the attention of the academia and the business [14-18]. Agryris and other scholars also modify the concept of entrepreneurial learning constantly.

Slater \& Narver (1995) also think market orientation has a close relationship with entrepreneurial learning, market orientation must be combined with entrepreneurial learning can they effectively improve entrepreneurial ability of enterprise. And through the investigation on senior director of Marketing Department and Unmarketing Department in 411 
U.S companies, Baker and Sinkula (1999) found organization's learning orientation (that is, the higher level of organizational learning ) and the market orientation has significant positive influence on enterprises' entrepreneurship, namely a company without learning or strong guidance [19-21], it's market-oriented behavior can seldom promote entrepreneurship more quickly than competitors. Moreover, Taiwan's scholar yi bing Lin also consider entrepreneurial learning as intermediate variable and Taiwan's high-teach enterprise as respondents, making a empirical research on the relationship among market orientation, entrepreneurial learning and entrepreneurial ability [22].

Innovation is a concept with multiple attributes. The more market-oriented enterprise is more inclined to develop products with high degree of novelty or use more advanced technology. Zaltman, Ducan and Holbek (1973) think we can more effectively achieve enterprise's goal by the appropriate market intelligence gathering, and later the enterprise innovation decision-making, execution and other business activities. They put forward a chain between market orientation, innovation and entrepreneurship [23]. Slater and Narver (1994) also think innovation is a kind of core value-creating capabilities, innovation and the success of new products come from market orientation and entrepreneurial learning. Jaworski and Kohli (1993) hold that market orientation essentially involves making some different or new responds to market situation, basically can be regarded as a kind of innovative behavior. Slater (1997) also put forward that combining market-oriented culture with entrepreneurial spirits results in successful innovation [24]. Based on the discussion above, we put forward the following hypothesis to verify:

H1: Market orientation has a positive impact on the emerging technology enterprises entrepreneurial learning

H2: Market orientation has a positive impact on the emerging technology enterprises innovative ways

H3: Market orientation has a positive impact on the emerging technology enterprises innovation capability

Entrepreneurial learning needs the process of acquiring, mining and managing new enterprise knowledge. A series of recent studies also pointed out that through creative learning, entrepreneurial learning could gain the innovation on products, technology and systems, which directly affect the entrepreneurial ability of emerging technology enterprises. Argyris and Schon (1978) think that under the same conditions, entrepreneurial learning would increase the enterprise innovation ability in the future. Stata (1989) found that entrepreneurial learning could cause innovation, especially in the industry of knowledge - intensive entrepreneurial learning could lead innovation. Mabey and Salaman (1995) also thought entrepreneurial learning is an important facter of keeping innovation; Glynn (1996) also thought entrepreneurial approach to learning and ability could not only affect the innovation in the initial stage but also affect the execution phase of innovation; Foster (1986) got the product innovation S learning curve infering from learning the experience curve [25]; however, McKee (1992) pointed out that different types of entrepreneurial learning could lead to different forms of innovation based on Foster's (1986) model, like single circulate learning would only lead to incre-menta 1 innovation, while discontinious innovation needed doubleloop learning to achieve, visible entrepreneurial learning stimulates enterprise innovation [26]. Studies have shown that, entrepreneurial learning is not only an important factor of building entrepreneurial ability but also the basis to obtain competitive advantage and improve the performance of growth. It has been confirmed by several studies that entrepreneurial learning promotes entrepreneurial ability, which has a positive effect, like Politis (2005)analyzed the entrepreneurial learning how to implement the opportunity recognition and reduce the novelty disadvantage and improve entrepreneurship [27], etc.

Based on the above discussion by scholars about the relationship between entrepreneurial learning and innovation, this study, we propose the following hypothesis to verify:

H4: Entrepreneurship study has important influence on emerging technology enterprise innovation way

H5: Entrepreneurship study has important influence on emerging technology enterprise entrepreneurial ability

Entrepreneurship in emerging technology enterprise mainly reflects in technology, products and process innovation. Now the classification of the innovative ways is divided according to the strength of the degree of innovation, namely the gradual innovation and breakthroughs. Gradual innovation refers to the enterprise gain knowledge by thinking, exploration, choices and rebuilding the existing methods, there are three measures: (1) Products belong to new products only in the style and service; (2) Products are improved on the basis of existing technology; (3) Products are improved on the basis of technological process; Breakthrough innovation mainly gain skills through adaption, experiment and practice, it has three measures: (1) The products in the market is a brand new performance; (2) New ideas were introduced during the development of products; (3) There are new technology and skills in the manufacture and development. Breakthrough technology innovation will change people's way of thinking and influence the adjustment in industrial structure, gradual technology is a gradual and continuous innovation caused by the existing technical improvement, these two kinds of innovation process is characterized by a series of "S" curve cycle of technology (de qiang Mei, Youyong, 2012). As for companies those who are good at using gradual innovation way, they have strong advantage in improving products and technology as well as the enhanced environmental changes inside and outside the enterprises.

Miller \& Friesen (1982) thought, a competency-based entrepreneurship enterprise will be more boldly innovate under the condition of the product market risk. Lumpkin \& Dess (1996) thought, entrepreneurial ability stressed a spirit of creating new industry which based on the existing practice [28], this often achieve by introducing radical innovation. Salavou \& Lioukas's (2003) empirical research found, compared with gradual innovation, entrepreneurial orientation is more advantageous to promote mutation technology innovation. Entrepreneurial orientation is not only beneficial to breakthrough innovation based on the market, but also promote breakthrough innovation based on the technology (Zhou, Yim \& Tse, 2005). Entrepreneurial orientation can create exploratory, risk preference behavior in the process of 


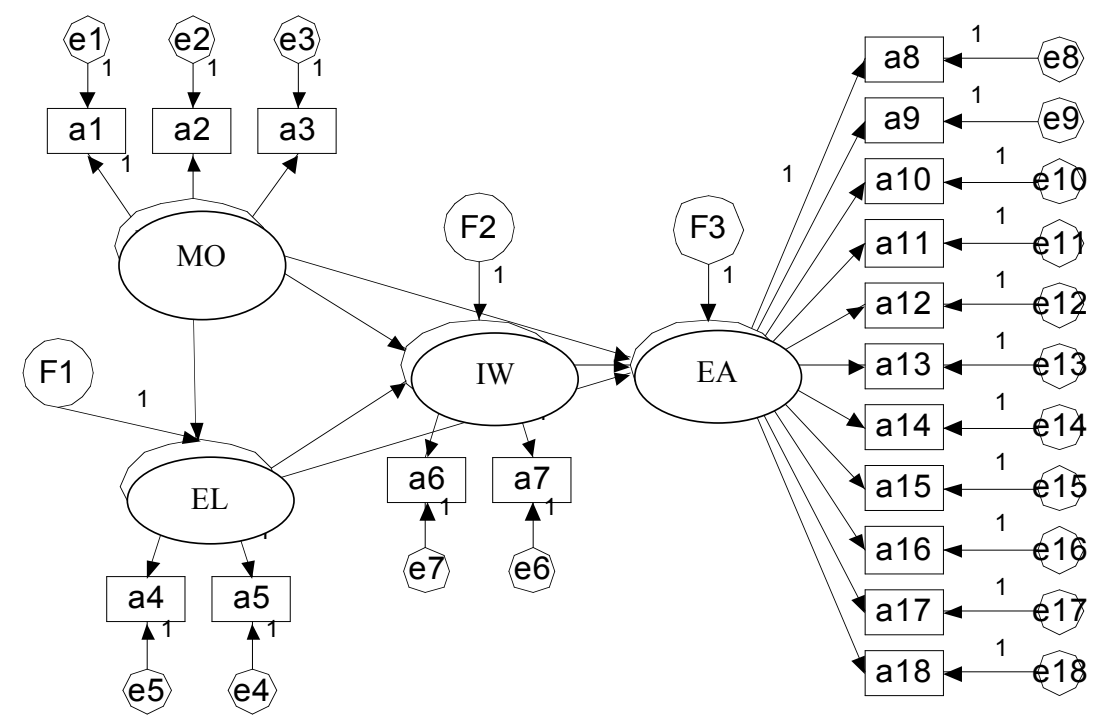

Fig. (1). Basic structure model and hypothesis.

product innovation, it promotes such values that market opportunities, risk endure and innovation to accept to move into it, thus raising the emerging technology enterprise entrepreneurship [29]. So the following assumption is put forward:

H6: Innovative ways have positive influence on the emerging technology enterprises entrepreneurship

By studying the existing literature, this article in view of more integrated redefines four latent variables of the emerging technology enterprises: market orientation (MO), entrepreneurial learning (EL), innovative way (IW) and entrepreneurial ability (EA), pointing out that customer orientation (a1), competitor orientation (a2) and coordination between various functions (a3) these three behavior constitute the market orientation, single-loop learning (a4) and double-loop learning (a5) form the two major dimensions of entrepreneurial learning, gradual innovation (a6) and breakthrough innovation (a7) are two important ways of innovation, consisting of two order 11 dimensions of entrepreneurial ability, namely two first-order dimensions of the relevant opportunities and related management ability, and 11 second-order dimension of relationship (a8), learning (a9), knowledge sharing (a10), innovation (a11), opportunity recognition (a12) and development (a13), which in first-order dimension of opportunities and organization (a14), coordination (a15), risk management (a16), strategic (a17), ability of concept (a18), which in management.

Therefore, in this paper, based on the above research, in combination with the practical situation of the emerging technology enterprises, to build the following emerging technology enterprises entrepreneurship ascension path conceptual model:

\section{STUDY DESIGN}

\subsection{The Data Source}

In this paper, to verify the hypothesis involves four latent variables, such as market orientation, entrepreneurial learn- ing, entrepreneurial way and entrepreneurial ability (As shown in Fig. 1). In order to measure the four latent variables, it's necessary to design scale and questionnaire. We designed a initial questionnaire contains 18 issues, including 3 market orientation, 2 entrepreneurial learning, 2 innovative way and 11 entrepreneurial ability. The scope of questionnaire survey and test is in 492 emerging technology enterprises in our country, has recycled 436 questionnaires, the recovery was $88.62 \%$. Among them, a total of 56 questionnaires with missing data. After rejecting invalid questionnaire, this research received 417 valid questionnaires, the effective rate was $84.76 \%$. Through questionnaire analysis we found that, there were no obvious aggregation phenomenon, stating that this survey was effective. Sample size meet the requirements of the SEM method. The scale of the problem set adopts li kete 7 point scale to measure measuring object's approval in the problem statement.

\subsection{The Empirical Test About the Emerging Technology Enterprises Entrepreneurship Ascension to the Concep- tual Model}

\subsubsection{The Reliability Test}

The reliability mainly refers to whether the questionnaire is precision. The reliability analysis involves consistency and stability of the test results, it's purpose is how to control and reduce the random error. If use questionnaire test theory of reliability, can use the following formula:

$r_{X X}=\frac{S_{T}^{2}}{S_{X}^{2}}$ or $r_{X X}=1-\frac{S_{E}^{2}}{S_{X}^{2}}$

Type in $S_{T}^{2}$ said true score variance $S_{X}^{2} S_{E}^{2}$, indicate take-home scores of variance; show the error variance.

There are 6 kinds of commonly used reliability coefficient: (1) retest reliability; (2) copy the reliability; (3) $1 / 2$ reliability; (4) Libraries have to -Richardson;(5) Cloning Bach reliability coefficient; (6) raters reliability. 
Table 1. The reliability statistics.

\begin{tabular}{|c|c|}
\hline Cronbach'sAlpha & Item \\
\hline \hline .826 & 18 \\
\hline
\end{tabular}

In this paper, reliability mainly adopts general inspection is Cronbach'a consistency coefficient, DeVellis thought, it's value in $0.65-0.70$ are the minimum acceptable values; if value within $0.70-0.80$, that the reliability of the questionnaire is good; if value within $0.80-0.90$, that the reliability of the questionnaire is very good. Therefore, a questionnaire with good reliability coefficient over 0.80 , using the SPSS17.0 to recycling effective questionnaire test, get the reliability statistical tests (Table 1) and correlation matrix of 20 topics (Table 2 ), from the variables of reliability Cronbach'a measurement model, questionnaire overall Cron- bach'a value reached 0.826 , indicates that the emerging technology enterprises entrepreneurship ascension path concept dimension has the very good reliability.

\subsubsection{Validity of the Test}

In the measurement theory, validity is defined as in a series of measurement, related to the purpose of measuring the true variance (that is, the effective variable) and the ratio of the total variance:

$$
r_{x y}^{2}=\frac{S_{v}^{2}}{S_{x}^{2}}
$$

$r_{x y}^{2}$ express measurement validity coefficient, $S_{v}^{2}$ stand for effective variables, $S_{x}^{2}$ stand for the total variance.

Table 2. A correlation matrix.

\begin{tabular}{|c|c|c|c|c|c|c|c|c|c|c|c|c|c|c|c|c|c|c|}
\hline & a1 & a2 & a3 & a4 & a5 & a6 & a7 & a8 & a9 & a10 & a11 & a12 & a13 & a14 & a15 & a16 & a17 & a18 \\
\hline al & 000 & .488 & .050 & .224 & 329 & .063 & 024 & .063 & .122 & .043 & -.016 & -.043 & .019 & .148 & .127 & .055 & -.021 & .030 \\
\hline $\mathrm{a} 2$ & .488 & 1.000 & .038 & -.164 & -.305 & .219 & .048 & .210 & .112 & .127 & .082 & .099 & .124 & .150 & .139 & .201 & .133 & .143 \\
\hline a3 & .050 & .038 & 1.000 & .073 & .246 & .045 & -.008 & -.018 & -.010 & .102 & .016 & .048 & .088 & .084 & -.022 & .012 & .136 & .033 \\
\hline $\mathrm{a} 4$ & -.224 & -.164 & .073 & 1.000 & .395 & .039 & .095 & .016 & -.030 & .025 & .002 & .018 & -.023 & .044 & .055 & .057 & .122 & .005 \\
\hline a5 & -.329 & -.305 & .246 & .395 & 1.000 & .000 & .080 & -.061 & -.118 & .009 & .014 & .086 & .037 & .131 & .088 & -.003 & .094 & .014 \\
\hline a6 & .063 & .219 & .045 & .039 & .000 & 1.000 & .644 & .541 & .282 & .531 & .548 & .448 & .419 & .313 & .379 & .433 & .443 & .380 \\
\hline a7 & -.024 & .048 & -.008 & .095 & .080 & .644 & 1.000 & .481 & .264 & .445 & .497 & .411 & .374 & .227 & .332 & .355 & .335 & .329 \\
\hline a8 & .063 & .210 & -.018 & .016 & -.061 & .541 & .481 & 1.000 & .344 & .445 & .431 & .366 & .243 & .293 & .299 & .322 & .310 & .269 \\
\hline a9 & .122 & .112 & -.010 & -.030 & -.118 & .282 & .264 & .344 & 1.000 & .334 & .321 & .264 & .198 & .236 & .182 & .242 & .174 & .182 \\
\hline a10 & .043 & .127 & .102 & .025 & .009 & .531 & .445 & .445 & .334 & 1.000 & .691 & .606 & .519 & .407 & .364 & .529 & .540 & .402 \\
\hline a11 & -.016 & .082 & .016 & .002 & .014 & .548 & .497 & .431 & .321 & .691 & 1.000 & .642 & .504 & .423 & .393 & .482 & .486 & .408 \\
\hline a12 & -.043 & .099 & .048 & .018 & .086 & .448 & .411 & .366 & .264 & .606 & .642 & 1.000 & .587 & .461 & .403 & .512 & .547 & .497 \\
\hline a13 & .019 & .124 & .088 & -.023 & .037 & .419 & .374 & .243 & .198 & .519 & .504 & .587 & 1.000 & .499 & .457 & .446 & .482 & .464 \\
\hline a14 & .148 & .150 & .084 & .044 & .131 & .313 & .227 & .293 & .236 & .407 & .423 & .461 & .499 & 1.000 & .498 & .411 & .444 & .439 \\
\hline a15 & .127 & .139 & -.022 & .055 & .088 & .379 & .332 & .299 & .182 & .364 & .393 & .403 & .457 & .498 & 1.000 & .333 & .361 & .356 \\
\hline a16 & .055 & .201 & .012 & .057 & -.003 & .433 & .355 & .322 & .242 & .529 & .482 & .512 & .446 & .411 & .333 & 1.000 & .670 & .491 \\
\hline a17 & -.021 & .133 & .136 & .122 & .094 & .443 & .335 & .310 & .174 & .540 & .486 & .547 & .482 & .444 & .361 & .670 & 1.000 & .533 \\
\hline a18 & .030 & .143 & .033 & .005 & .014 & .380 & .329 & .269 & .182 & .402 & .408 & .497 & .464 & .439 & .356 & .491 & .533 & 1.000 \\
\hline
\end{tabular}

Table 3. KMO and Bartlett's test.

Sampling Enough Degrees of Kaiser - Meyer - Olkin Measurements 


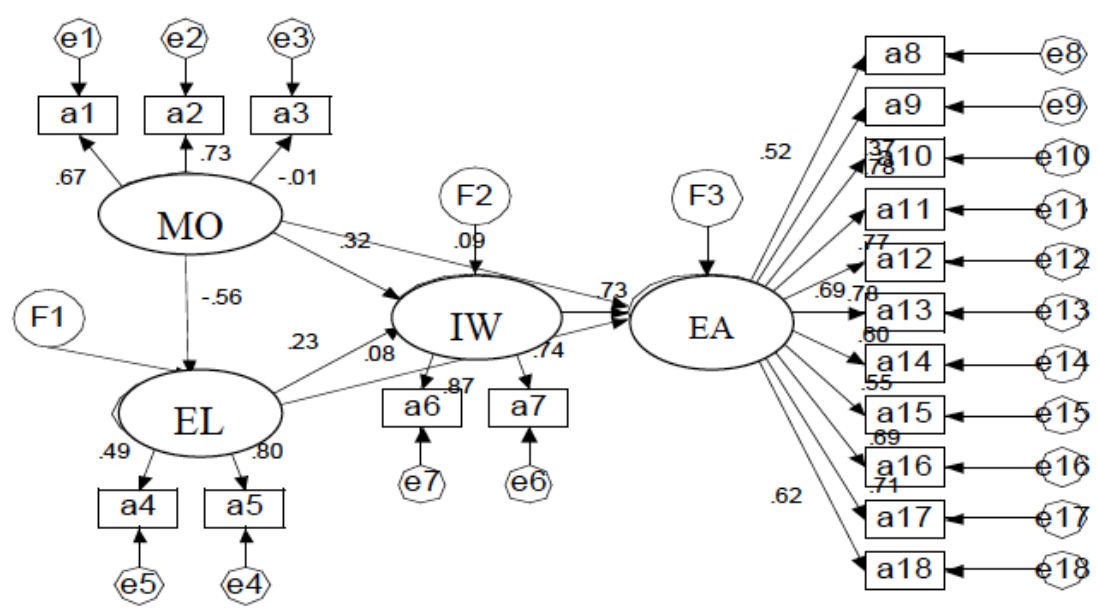

Fig. (2). Emerging technology enterprises entrepreneurship ascension path conceptual model test.

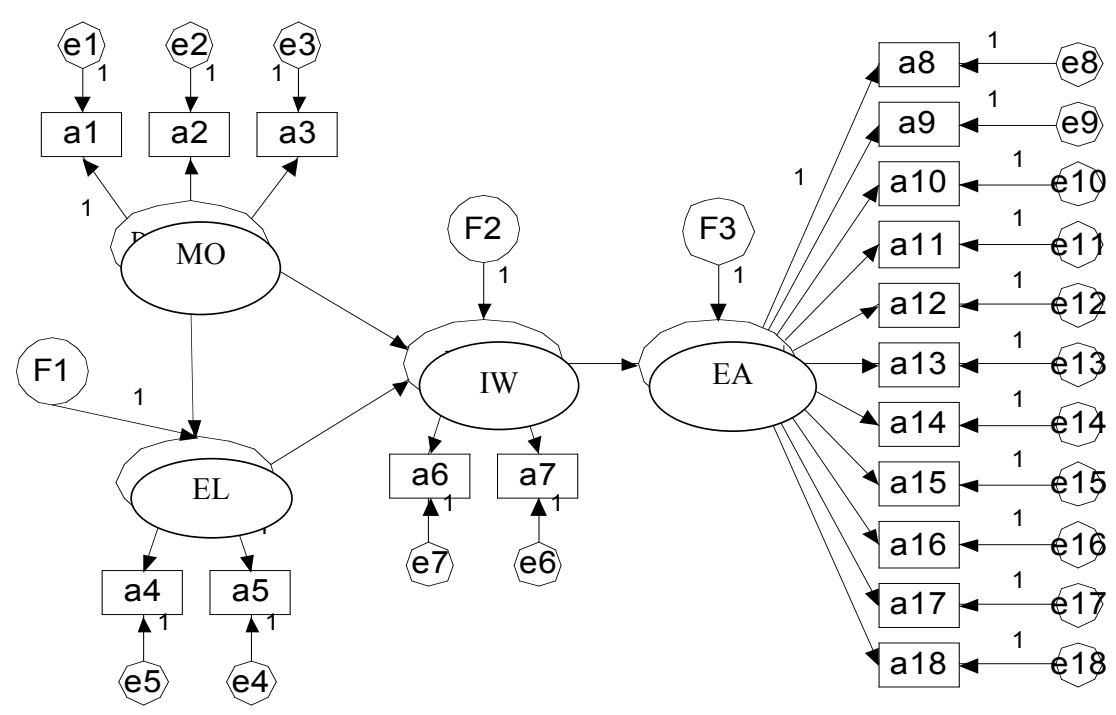

Fig. (3). Revised the emerging technologies of corporate entrepreneurship ascension path conceptual models two.

Generally there are three kinds of commonly used validity index: (1) Content validity; (2) Criterion validity; (3) Construct validity.

As shown in Table 3, judging from KMO and Bartlett ball inspection of factor analysis, Chi-square value is $2898.194(\mathrm{df}=153)$ there was no significant difference between observations and expectations. KMO statistics. (888) also suggests that sample is very suitable for factor analysis. So the sample can better support scale, namely good validity.

\section{MODEL TEST}

The fit of the structural equation model of inspection, tests whether hypothesis model and real data sample is consistency. There are many measurements about the overall fit of the model, goodness of fit is the most commonly used fitting index card square test. In fact, Chi-square test here is fitting a measure of the inferior degree 0 , that is to say, a small card square value explain fitting is good, but the chisquare values associated with sample size, making it not well for determining model fitting, in order to reduce the influence of sample size for fitting test, there is a rough regular which directly associated with chi-square, the ratio of the Chi-square value and degrees of freedom is less than 3, then you can think model fitting is good. In addition to, there are many index of model fitting test, but different indicators under different sample size, model complexity have different performance characteristics, it must be conducted according to the specific situation carefully. In this paper, according to the results of the correlation matrix of Table 2 item, using maximum likelihood method of AMOS17.0 to estimate model, preliminary operation result is shown in Fig. (2).

According to the results of AMOS17.0 output, from the view of the actual research, we only focused on the Default model. For Saturated model, refers to AMOS can fitting model with few restrictions, because in many cases, it does not provide the corresponding value, which could not judge the merits of the model, so it doesn't need to focus on ;and Independence model is that AMOS can fit with the most restrictions on models, namely there is no correlation between the introduced scalar case calculation results, so we usually focus on the prediction results of the model Table 4 is AMOS output and sorted, part of the index is not model fitting effect evaluation index, so the last column has no 
Table 4. Emerging technology enterprises entrepreneurship ascension path concept model fitting index.

\begin{tabular}{|c|c|c|c|c|c|}
\hline \multicolumn{2}{|c|}{ Macro } & \multirow{2}{*}{$\begin{array}{c}\text { Default Model } \\
42\end{array}$} & \multirow{2}{*}{$\begin{array}{c}\text { Saturated Model } \\
171\end{array}$} & \multirow{2}{*}{$\begin{array}{c}\text { Independence Model } \\
18\end{array}$} & \multirow[t]{2}{*}{ Evaluation Standard } \\
\hline \multirow{5}{*}{ CMIN } & NPAR & & & & \\
\hline & CMIN & 503.025 & .000 & 2946.5395 & \\
\hline & $\mathrm{DF}$ & 129 & 0 & 153 & \\
\hline & $\mathrm{P}$ & .000 & & .000 & $>0.05$ \\
\hline & CMIN/DF & 3.899 & & 19.259 & $<3$ \\
\hline \multirow{4}{*}{ RMR, GFI } & RMR & .049 & .000 & .189 & the smaller the better \\
\hline & GFI & .874 & 1.000 & .367 & $>0.9$ \\
\hline & AGFI & .833 & & .292 & $>0.9$ \\
\hline & PGFI & .660 & & .328 & $>0.5$ \\
\hline \multirow{5}{*}{$\begin{array}{c}\text { Baseline } \\
\text { Comparisons }\end{array}$} & NFIDelta 1 & .829 & 1.000 & .000 & $>0.9$ \\
\hline & RFIrho1 & .798 & & .000 & $>0.9$ \\
\hline & IFIDelta2 & .867 & 1.000 & .000 & $>0.9$ \\
\hline & TLIrho2 & .841 & & .000 & $>0.9$ \\
\hline & $\mathrm{CFI}$ & .866 & 1.000 & .000 & $>0.9$ \\
\hline \multicolumn{2}{|c|}{ Macro } & Default Model & Saturated Model & Independence Model & Evaluation Standard \\
\hline \multirow{3}{*}{$\begin{array}{c}\text { Parsimony-Adjusted } \\
\text { Measures }\end{array}$} & PRATIO & .843 & .000 & 1.000 & \\
\hline & PNFI & .699 & .000 & .000 & $>0.5$ \\
\hline & PCFI & .730 & .000 & .000 & $>0.5$ \\
\hline \multirow{3}{*}{$\mathrm{NCP}$} & $\mathrm{NCP}$ & 374.025 & .000 & 2793.595 & the smaller the better \\
\hline & LO90 & 308.878 & .000 & 2620.958 & \\
\hline & HI90 & 446.739 & .000 & 2973.565 & \\
\hline \multirow{4}{*}{ FMIN } & FMIN & 1.209 & .000 & 7.803 & \\
\hline & F0 & .899 & .000 & 6.715 & the smaller the better \\
\hline & LO90 & .742 & .000 & 6.300 & \\
\hline & HI90 & 1.074 & .000 & 7.148 & \\
\hline \multirow{4}{*}{ RMSEA } & RMSEA & .083 & & .210 & the smaller the better \\
\hline & LO90 & .076 & & .203 & \\
\hline & HI90 & .091 & & .216 & \\
\hline & PCLOSE & .000 & & .000 & the smaller the better \\
\hline \multirow{4}{*}{ AIC } & AIC & 587.025 & 342.000 & 2982.595 & the smaller the better \\
\hline & $\mathrm{BCC}$ & 591.045 & 358.368 & 2984.318 & the smaller the better \\
\hline & $\mathrm{BIC}$ & 756.415 & 1031.658 & 3055.191 & the smaller the better \\
\hline & CAIC & 798.415 & 1202.458 & 3073.191 & the smaller the better \\
\hline \multirow[t]{4}{*}{ ECVI } & ECVI & 1.411 & .822 & 7.170 & the smaller the better \\
\hline & LO90 & 1.255 & .822 & 6.755 & \\
\hline & HI90 & 1.586 & .822 & 7.602 & \\
\hline & MECVI & 1.421 & .861 & 7.174 & the smaller the better \\
\hline \multirow[t]{2}{*}{ HOELTER } & HOELTER.05 & 130 & & 26 & $>200$ \\
\hline & HOELTER.01 & 140 & & 28 & $>200$ \\
\hline
\end{tabular}


Table 5. RegressionWeights:(Groupnumber1-Defaultmodel).

\begin{tabular}{|l|c|c|c|c|c|c|c|}
\hline & & & Estimate & S.E. & C.R. & Pabel \\
\hline \hline Entrepreneurial learning & $<---$ & Market orientation & .756 & .114 & 6.654 & $* * *$ & par_1 \\
\hline Approach to innovation & $<---$ & Market orientation & .334 & .107 & 3.123 & .002 & par_2 \\
\hline Approach to innovation & $<---$ & Entrepreneurial learning & .180 & .083 & 2.162 & .031 & par_3 \\
\hline Entrepreneurial ability & $<---$ & Approach to innovation & .710 & .081 & 8.714 & $* * *$ & par_4 \\
\hline Entrepreneurial ability & $<---$ & Market orientation & .088 & .075 & 1.164 & .245 & par_5 \\
\hline Entrepreneurial ability & $<---$ & Entrepreneurial learning & .060 & .055 & 1.083 & .279 & par_6 \\
\hline
\end{tabular}

Table 6. Regression weights: (Group number 1-default model).

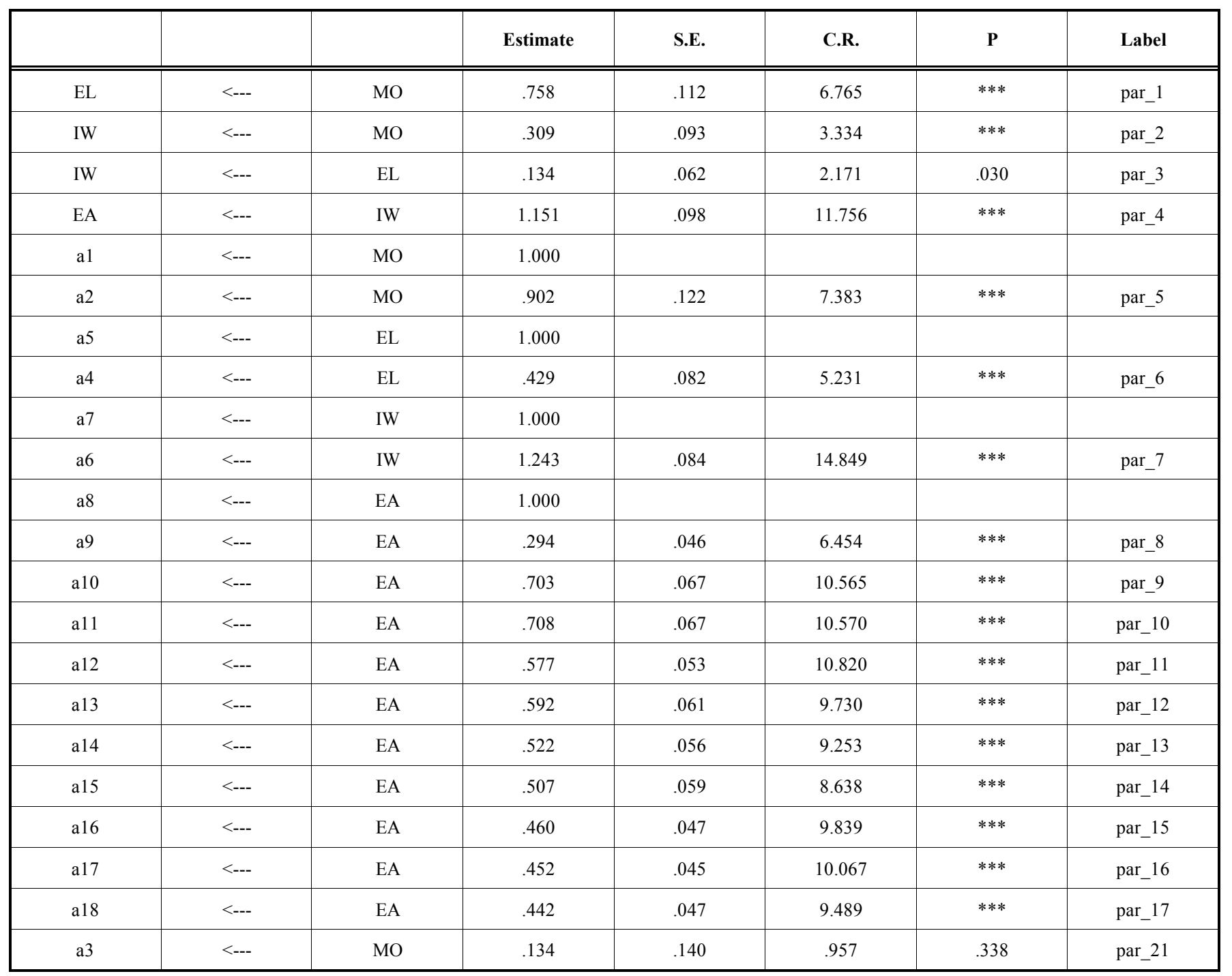

corresponding evaluation standard. From the perspective model fitting effect, in the absolute indicators fitting effect, Chi-square value does not reach the acceptable significant level, because it's easy to influenced by such factors as the sample size, here ignores the $\mathrm{P}$ value. The only part of the Table 4 indexes reach an acceptable level, some indicators such as absolute indicators $\mathrm{GFI}=0.874, \mathrm{AGFI}=0.833$, in the relative indicators fitting effect, $\mathrm{NFI}=0.829, \mathrm{IFI}=0.867$, $\mathrm{TLI}=0.841$

Close to 0.9; the RFI $=0.798$ is smaller; in the alternative indicators, $\mathrm{CFI}=0.866$, $\mathrm{RMSEA}=0.083>0.08$. 


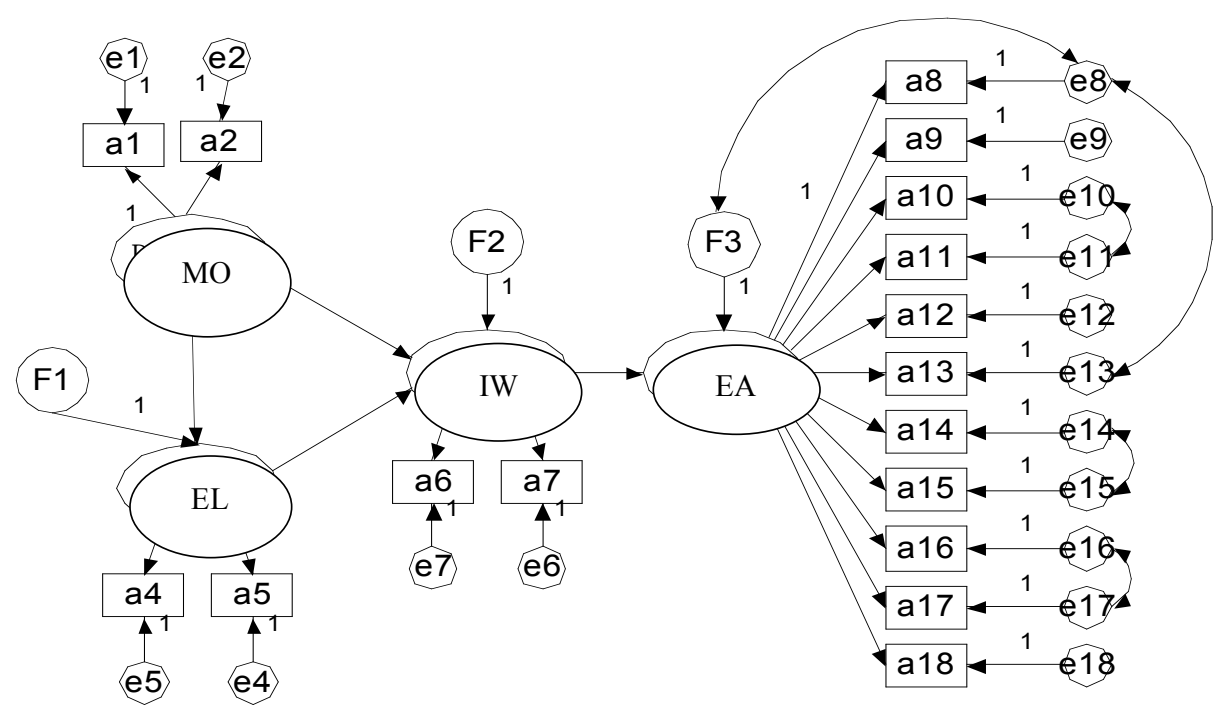

Fig. (4). Again the revised emerging technology enterprises entrepreneurship ascension path conceptual models three.

So, comprehensive above all kinds of evaluation indexes, we think that the fitting effect of the model, we need to modify it.

\section{CORRECTION OF THE MODEL}

Coefficient of evaluation results in Table 5 .

From the Table $\mathbf{5}$ we can know, path coefficient under 0.05 level was not significant, the other parameters can be, first consider deleting this path from entrepreneurial learning to entrepreneurial ability, after the inspection, it's still not clear from Market orientation to the entrepreneurial ability structure coefficient, therefore, it should be considered to be deleted, the modified model is shown in Fig. (3).

In the revised model two, Amos to find the solution by using maximum likelihood estimation, after six times correction according to the evaluation standard, the results in Table 6.

From the point $\mathrm{p}$ values, using a a 3 observation variable to measure market orientation, the $\mathrm{P}$ values failed to meet the requirements, should be deleted, the final model as shown in Fig. (4).

In model test in Fig. (4), Table 7 can be obtained, from the perspective model fitting effect, Chi-square freedom than a fair result is obtained, GFI $=0.931>0.90, \quad$ AGFI $=0$. $904>0.90, \mathrm{PGFI}=0.669>0.5$; In the relative indicators fitting effect, NFI $=0.910, \mathrm{IFI}=0.946, \mathrm{TLI}=0.93$ more than 0.9 , and RFI $=0.89$ is close to 0.9 , PNFI $=0.74>0.5$; In the alternative indicators, $\mathrm{CFI}=0.945>0.9, \quad \mathrm{PCFI}=0.76>0.5$, RMSEA $=0.06<0.08$. Therefore, integrated above all kinds of evaluation index, we think the model fitting effect is good. 11)

The optimal model parameters estimation show (Table 8-

\section{THE MODEL EXPLANATION}

For correction of the final model, Amos output between the latent variables of direct effect and indirect effect and total effect relationship:

\subsection{Direct Effect}

Refers to directly affected by reason to the result variables, with reason variables to the result of path coefficient to measure the effect directly. Table 8 illustrates, the standardized path coefficient from innovative ways to the entrepreneurship is 0.341 , the direct effect from market orientation to innovation method is 0.736 . This shows that when the other conditions unchanged, "city innovation way" latent variables each increases 1 units, "entrepreneurship" latent variables will directly improve 0.736 units.

\subsection{The Indirect Effect}

Refers to reason variable indirectly influence the results variable through affecting one or more intermediary variables. When only one mediation variables, the size of the indirect effect is the product of two path coefficient. Such as using the results of the last column of Table 8, the standardization of entrepreneurial learning to innovation way path coefficient is 0.239 , innovative ways to the standardization of entrepreneurship path coefficient is 0.736 , then the indirect effect from market orientation to the entrepreneurship is $0.239 * 0.736=0.176$. This shows that when the other conditions unchanged, "entrepreneurial learning" latent variables 1 unit each ascending, "entrepreneurship" latent variables will indirectly increase 0.176 units.

\subsection{The Total Effect}

By reason to the result variables in general, it is the sum of direct effect and indirect effect. Such as using the results of the Table 8 the last column, entrepreneurial learning to the indirect effect of entrepreneurship is 0.176 , the entrepreneurial learning to the direct effect of entrepreneurship is 0 , entrepreneurial learning to the overall effect of entrepreneurship is $0.176+0=0.176$. This shows that when the other conditions unchanged," entrepreneurial learning" latent variables each increases 1 units, a total of "entrepreneurship" latent variables will increase 0.176 units. 
Table 7. Emerging technology enterprises entrepreneurship ascension path concept model fitting index.

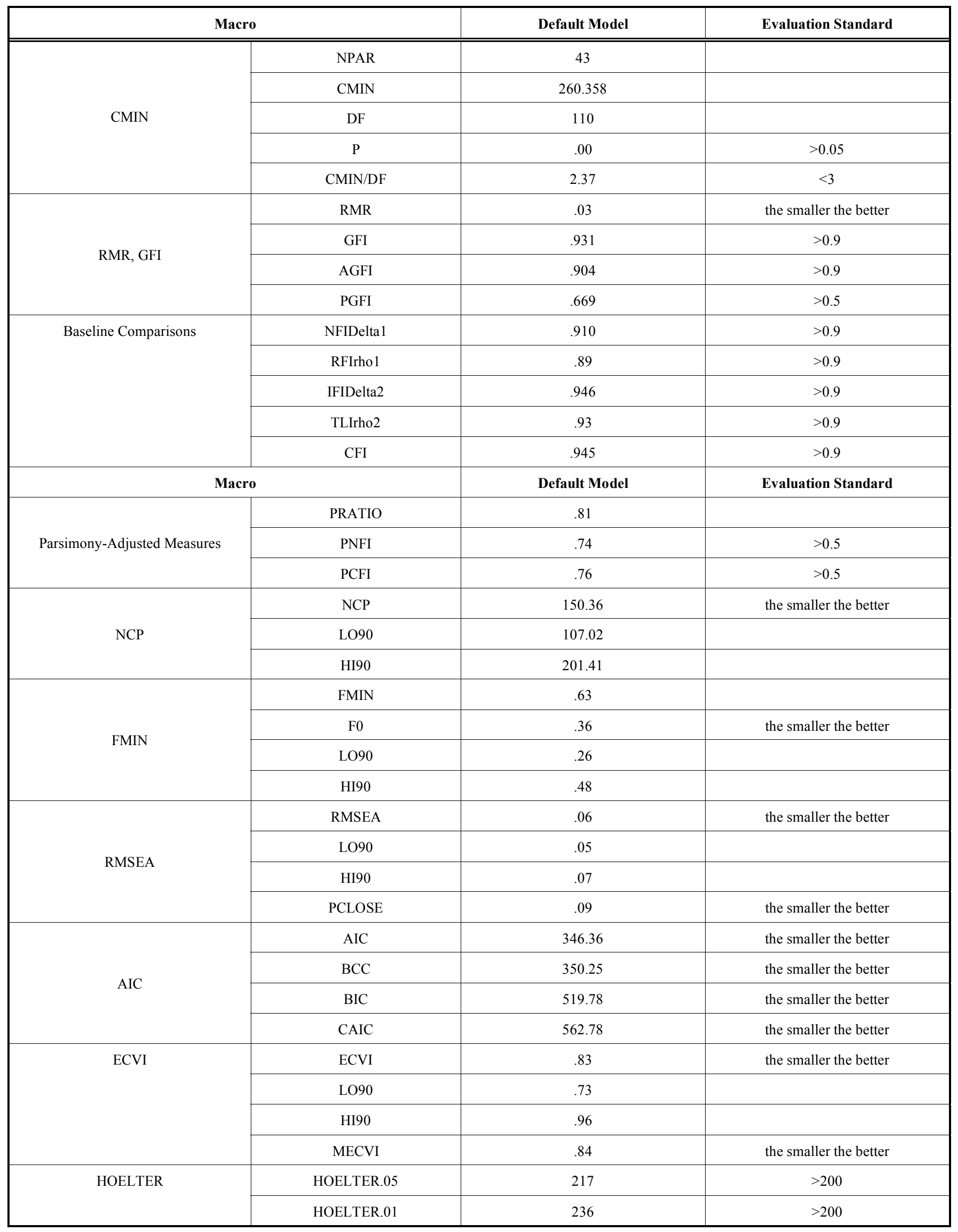


Table 8. Regression weights: (Group number 1-default model).

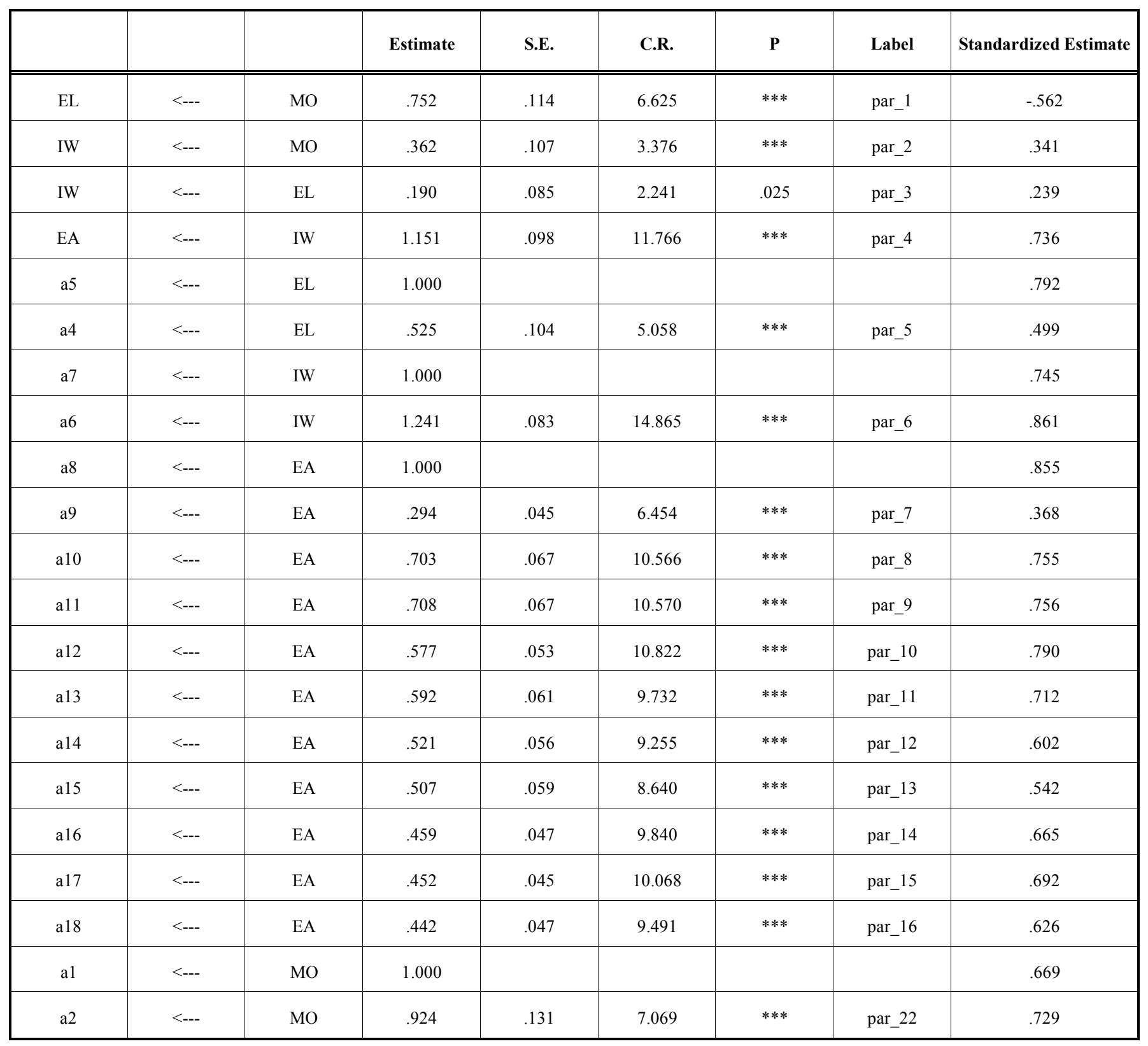

Table 9. Covariances: (Group number 1-default model).

\begin{tabular}{|c|c|c|c|c|c|c|c|}
\hline & & & Estimate & S.E. & C.R. & Pabel \\
\hline \hline $\mathrm{e} 16$ & $<-->$ & $\mathrm{e} 17$ & .08 & .01 & 6.48 & $* * *$ & par_17 \\
\hline $\mathrm{e} 10$ & $<-->$ & $\mathrm{e} 11$ & .09 & .02 & 4.38 & $* * *$ & par_18 \\
\hline $\mathrm{e} 14$ & $<-->$ & $\mathrm{e} 15$ & .12 & .03 & 4.69 & $* * *$ & par_19 \\
\hline $\mathrm{e} 8$ & $<->$ & $\mathrm{e} 13$ & -.09 & .03 & -3.65 & $* * *$ & par_20 \\
\hline $\mathrm{e} 8$ & $<->$ & $\mathrm{F} 3$ & -.34 & .08 & -4.04 & $* * *$ & par_21 \\
\hline
\end{tabular}


Table 10. Correlations: (Group number 1-default model).

\begin{tabular}{|c|c|c|c|}
\hline & & & Estimate \\
\hline \hline $\mathrm{e} 16$ & $<->$ & $\mathrm{e} 17$ & .39 \\
\hline $\mathrm{e} 10$ & $<->$ & $\mathrm{e} 11$ & .28 \\
\hline $\mathrm{e} 14$ & $<-->$ & $\mathrm{e} 15$ & .26 \\
\hline $\mathrm{e} 8$ & $<->$ & $\mathrm{e} 13$ & -.17 \\
\hline $\mathrm{e} 8$ & $<->>$ & F3 & -.55 \\
\hline
\end{tabular}

Table 11. Variances: (Group number 1-default model).

\begin{tabular}{|c|c|c|c|c|c|}
\hline & Estimate & S.E. & C.R. & $\mathbf{P}$ & Label \\
\hline MO & .31 & .06 & 5.40 & $* * *$ & par_23 \\
\hline $\mathrm{F} 1$ & .38 & .11 & 3.56 & $* * *$ & par_24 \\
\hline $\mathrm{F} 2$ & .32 & .04 & 7.82 & $* * *$ & par_25 \\
\hline e1 & .38 & .05 & 7.84 & $* * *$ & par_27 \\
\hline e2 & .23 & .04 & 6.03 & $* * *$ & par_28 \\
\hline e4 & .33 & .11 & 3.11 & .00 & par_29 \\
\hline e7 & .19 & .03 & 6.38 & $* * *$ & par_32 \\
\hline e8 & .99 & .10 & 10.22 & $* * *$ & par_33 \\
\hline e9 & .47 & .03 & 14.16 & $* * *$ & par_34 \\
\hline $\mathrm{e} 10$ & .32 & .03 & 11.95 & $* * *$ & par_35 \\
\hline e11 & .32 & .03 & 11.94 & $* * *$ & par_36 \\
\hline $\mathrm{e} 12$ & .17 & .01 & 11.59 & $* * *$ & par_37 \\
\hline e18 & .26 & .02 & 13.34 & $* * *$ & par_43 \\
\hline
\end{tabular}

\section{CONFLICT OF INTEREST}

The authors confirm that this article content has no conflict of interest.

\section{ACKNOWLEDGEMENTS}

The project supported by Outstanding Scientific and Technological Personnel Training Funds of University of 
Science and Technology Liaoning: Research on the emerging technology enterprises in our country entrepreneurship ability ascending path -Julong group for example 2013RC09; Liaoning Province Education Science "Twelfth Five Year Plan" project "Internet + University Entrepreneurship Education" platform design JG15DB176.

\section{REFERENCES}

[1] J. J. Liu, "Study on the Entrepreneurial Learning Mode and its Effect Mechanism on New Venture Growth", Science \& Technology Progress and Policy, vol. 27, no. 20, pp. 70-73, 2010.

[2] S. Yan, and Y. Lu., "Characteristics and speciation of emerging technology path research", Journal of Management, vol. 20, no. 2, pp. 53-62, 2007.

[3] D. Politis, "The process of entrepreneurial learning: Aconceptual framework", Entrepreneurial Theory \& Practice, vol. 18, no. 4, pp. $32-45,2005$

[4] Y. Lu, Z. G. Shi, M. Wang, H. Y. Zhang, and J. Liu, "Emerging technologies: the concept, characteristics and management of new thinking", Journal of modern management science, vol. 42, no. 4, pp. 153-171, 2005.

[5] P. Xu, "Emerging technology enterprise boundary problem research", Science and technology management research, vol. 34, no. 7, pp. 12-18, 2008.

[6] S. G. Winter, "The Satisficing Principle in Capability Learning", Strategic Management Journal, vol. 12, no. 21, pp. 51-64, 2000.

[7] Y. L. Zhang, and X. W. Wang, "Entrepreneurs to previous experience, learning style and the empirical study of entrepreneurship", Journal of Management Science, vol. 16, no. 3, pp. 23-35, 2011.

[8] S. Shane and S. Venkataraman, "The promise of entrepreneurship as a field of research", Academy of Management Review, vol. 14, no. 25 , pp. $123-132,2000$.

[9] N. Nicolaou, "Is the tendency to engage in entrepreneurship genetic?" Management Science, vol. 26, no. 54, pp. 13-24, 2008.

[10] H. M. Xie, C. Y. Liu, and C. H. Chen, "The relationship between market orientation and organizational performance organizational learning and innovation: an empirical study of the influence of water - the pearl river delta region enterprises", Management of the World, vol. 18, no. 2, pp. 80-94, 2006.

[11] L. B. Rasmussen and T. Nielsen, "Entrepreneurial capabilities:Is entrepreneurship action research in disguise?" A.I. \& Soc., vol. 26, no. 18, pp. 130-142, 2004.

[12] C. L. Wang, P. K. Ahmed, and D. Capabilities, "A Review and Research Agenda", International Journal of Management Reviews, vol. 116, no. 9, pp. 138-147, 2007.

[13] D. J. Teece, "Explicating Dynamic Capabilities: The Nature and Microfoundations of (Sustainable) Enterprise Performance", Strategic Management Journal, vol. 106, no. 28, pp. 133-145, 2007.

[14] R. Wood, and A. Bandura, "Social Cognitive Theory of Organizational Management", Academy of Management Review, vol. 126, no. 14, pp. 27-35, 1989.
[15] C. C., Chen, P. G. Greene, and A. Crick, "Does Entrepreneurial Self-efficacy Distinguish Entrepreneurs from Managers?" Journal of Business Venturing, vol. 22, no. 13, pp. 26-34, 1998.

[16] A. DeNoble., D. Jung, and S. Ehrlich, "Initiating New Ventures: The Role of Entrepreneurial Self-efficacy", Babson Research Conference, Babson College. Boston. MA, pp. 26-44, 1999.

[17] T. W. Y. Man, T. Lau, and K. F. Chan, "The competitiveness of small and medium enterprises: A conceptualization with focus on entrepreneurial competencies", Journal of Business Venturing, vol. 28 , no. 17, pp. 126-134, 2002.

[18] J. Tang, Y.F. Jiang, "The concept of entrepreneurship theory building and empirical test", Science, and Science and Technology Management, vol. 122, no. 8, pp. 121-134, 2008.

[19] D. Q. Mei, and Y. You, "High and new technology enterprise entrepreneurship, innovation type and study on the relationship between the financing way", Journal of technology innovation management, vol. 12, no. 1, pp. 8-14, 2012.

[20] D., Miller, and E. Friesen, "Innovation in Conservative and Entrepreneurial Firms: Two Models of Strategic Momentum", Strategic Management Journal, vol. 32, no. 3, pp. 38-44, 1982.

[21] G. Lumpkin, and G. Dess, "Clarifying the Entrepreneuria1 Orientation Construct and Linking it to Performance", Academy of Management Review, vol. 42, no. 21, pp. 29-38, 1996.

[22] H. Salavou, and S. Loiukas, "Radical Product Innovations in SMEs: The Dominance of Entrepreneuria1 Orientation", Creativity and Innovation Management, vol. 32, no. 12, pp. 65-76, 2003.

[23] K. Z. Zhou, C.K. Yim, D. K. Tse, "The Effects of Strategic Orientations on Technology and Market -based Break through Innovations", Journal of Marketing, vol. 122, no. 69, pp. 23-31, 2005.

[24] S. A. Zahra, "Emerging multinationals venturing into developed economies: Implications for learning, unlearning, and entrepreneurial capability", Journal of Management Inquiry, vol. 46, no. 20, pp. 132-146, 2011.

[25] Z. Y. Zhao, Y. Lu, and C. Hong, "Emerging technology challenge to traditional management and the special marketing idea", China Soft Science, vol. 12, no. 7, pp. 13-24, 2004.

[26] D. C. Leonard, A. P. Pons, and S. S. Asfour, "Realization of a Universal Patient Identifier for Electronic Medical Records Through Biometric Technology," IEEE Transactions on Information Technology in Biomedicine, vol. 13, pp. 494-500, 2009. doi: 10.1 109/TITB.2008.926438.

[27] K. Ogawa, "optical probe current sensor module using the Kerr effect of exchange-coupled magnetic film and its application to IGBT switching current measurements " The International Journal on Smart Sensing and Intelligent Systems, vol. 5, no. 2, pp. 347 361, 2012.

[28] Y. M. Luo, P. Z. Liu, and M. H., Liao, "An artificial immune network clustering algorithm for mangroves remote sensing," International Journal on Smart Sensing and Intelligent Systems, vol. 7, no. 1, pp. 116-134, 2014.

[29] D. D. Zhang, "Research on Chips' Defect Extraction Based On Image-Matching", International Journal on Smart Sensing and Intelligent Systems, vol. 7, no. 1, pp. 321-336, 2014.

\footnotetext{
Received: September 16, 2014

(C) Dayong Xu; Licensee Bentham Open.
}

Revised: December 23, 2014

Accepted: December 31, 2014

This is an open access article licensed under the terms of the (https://creativecommons.org/licenses/by/4.0/legalcode), which permits unrestricted, noncommercial use, distribution and reproduction in any medium, provided the work is properly cited. 